\title{
Erratum to: Differences in Varroa destructor infestation rates of two indigenous subspecies of Apis mellifera in the Republic of South Africa
}

\author{
Ashley N. Mortensen ${ }^{1} \cdot$ Daniel R. Schmehl ${ }^{1,2}$. \\ Mike Allsopp $^{3}$ - Tomas A. Bustamante ${ }^{1}$. Chase B. Kimmel ${ }^{1}$ • \\ Mark E. Dykes ${ }^{4} \cdot$ James D. Ellis $^{1}$
}

Published online: 4 February 2016

(C) Springer International Publishing Switzerland 2016

\section{Erratum to: Exp Appl Acarol DOI 10.1007/s10493-015-9999-8}

Due to an unfortunate turn of events, the legend of Fig. 1 in the above-mentioned publication is missing. The correct representation of Fig. 1 and its caption are published here and should be treated as definitive.

The online version of the original article can be found under doi:10.1007/s10493-015-9999-8.

Ashley N. Mortensen

mortensena@ufl.edu

1 Entomology and Nematology Department, University of Florida, 970 Natural Area Drive, Steinmetz Hall, Gainesville, FL 32611, USA

2 Present Address: Bayer Crop Science, 2 T.W. Alexander Drive, Research Triangle Park, NC 27709, USA

3 ARC-Plant Protection Research Institute, P/Bag X5017, Stellenbosch 7599, South Africa

4 Texas Apiary Inspection Service, Department of Entomology, Texas A\&M University, 2475

TAMU, College Station, TX 77843-2475, USA 


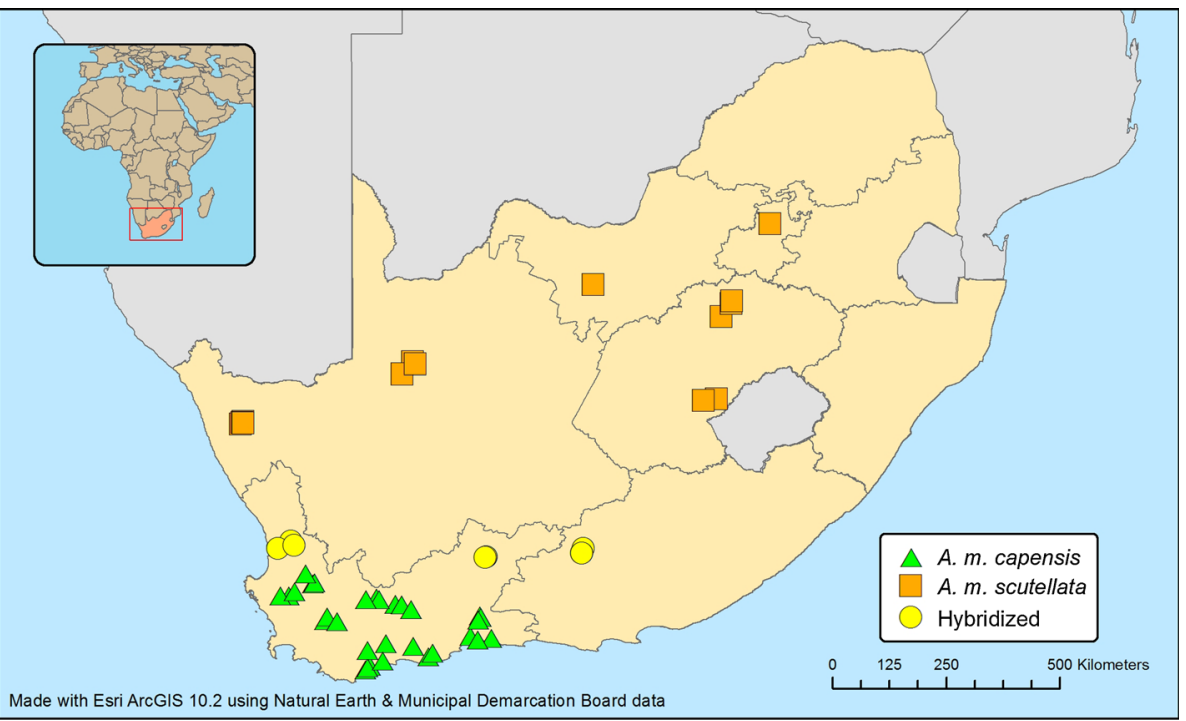

Fig. 1 Apiaries from which honey bee collections were made in the Republic of South Africa. A total of 586 colonies were sampled, with a minimum of 15 sampled colonies distributed between 1 and 4 apiaries per location. Host colony subspecies (Apis mellifera scutellata, A. m. capensis, or hybridized) was determined via classic morphometric analyses (Hepburn et al. 1998) 